\title{
Development of an Electrochemical Procedure for Monitoring Hydrogen Sorption/Desorption in Steel
}

\author{
Berk Ozdirik, (®a,b,z Kitty Baert, ${ }^{a}{ }^{\text {Tom }}$ Depover, ${ }^{\text {b Jean Vereecken, }}{ }^{\text {a,* }}$ Kim Verbeken, ${ }^{\text {b }}$ \\ Herman Terryn, ${ }^{a, *}$ and Iris De Graeve ${ }^{a, b}$
}

\author{
${ }^{a}$ Research Group Electrochemical and Surface Engineering (SURF), Department of Materials and Chemistry, \\ Vrije Universiteit Brussel, Pleinlaan 2, B-1050 Brussel, Belgium \\ ${ }^{b}$ Department of Materials, Textiles and Chemical Engineering, Ghent University (UGent), Technologiepark 903, \\ B-9052 Ghent, Belgium
}

\begin{abstract}
Hydrogen embrittlement leads to mechanical degradation of metals. Hence, hydrogen sorption/desorption properties of metals need to be characterized. An electrochemical procedure based on cyclic voltammetry (CV) and potentiostatic polarization is elaborated on plain-carbon steel. The procedure consists of first two consecutive CV cycles (pretreatment and reference CV), followed by cathodic $\mathrm{H}$-charging, and subsequent $\mathrm{CV}$ scans to study and quantify the $\mathrm{H}$-sorption/desorption. Best practice in this procedure is to perform all steps consecutively without interruption or sample manipulations between steps to avoid spontaneous $\mathrm{H}$-loss. The $\mathrm{H}$-related interaction with the steel is clearly identified in the CV and can be differentiated from the electrolyte contribution coming from thiourea. The study confirms the role of thiourea as H-recombination poison in alkaline solution, and also demonstrates that it contributes to the $\mathrm{CV}$ response. Additionally, various charging times are investigated to study the time to $\mathrm{H}$-saturation, and also the scan rate during the $\mathrm{CV}$ procedure is varied to study time-related phenomena. Dedicated discharging experiments were included in the study to complement the CV data, giving additional insights in the H-steel interaction. Moreover, hydrogen related findings are successfully verified by using a complimentary method, i.e. hot extraction. The better understanding of the peaks in the CV and the continuous procedure result in a reliable methodology to characterize the $\mathrm{H}$-sorption/desorption in steel.

(C) The Author(s) 2017. Published by ECS. This is an open access article distributed under the terms of the Creative Commons Attribution Non-Commercial No Derivatives 4.0 License (CC BY-NC-ND, http://creativecommons.org/licenses/by-nc-nd/4.0/), which permits non-commercial reuse, distribution, and reproduction in any medium, provided the original work is not changed in any way and is properly cited. For permission for commercial reuse, please email: oa@electrochem.org. [DOI: 10.1149/2.0521713jes] All rights reserved.

(cc) BY-NC-ND
\end{abstract}

Manuscript submitted June 23, 2017; revised manuscript received September 21, 2017. Published September 30, 2017.

Hydrogen embrittlement is the phenomenon leading to mechanical degradation of metals, in particular, a loss of ductility and toughness. The intensity of hydrogen degradation depends on many factors related to the nature of hydrogen and the material itself. Hydrogen can be incorporated in steel during the manufacturing process as well as during various stages of its use. After hydrogen absorption, it diffuses into the microstructure and is distributed between interstitial sites in the metal lattice and its structural defects. The hydrogen in the microstructure can roughly be classified in two forms, diffusible and trapped hydrogen. ${ }^{1}$ Although the term diffusible hydrogen has multiple descriptions in literature, it can be considered as the hydrogen that can move between lattice positions within a reasonable time frame according to the laws of diffusion. On the other hand, hydrogen that resides for a longer time near microstructural inhomogeneities (interfaces, grain boundaries, precipitates) as well as hydrogen accumulated in micro cracks and blisters, is called trapped. ${ }^{2}$ Depending on the binding energy of hydrogen to the trapping sites, trapped hydrogen can be classified as reversible or irreversible. ${ }^{3-6}$ To study the hydrogen-trap interaction, thermal desorption spectroscopy (TDS) can be used. By means of this method, an activation energy of the traps can be determined and the traps can be categorized as reversible or irreversible, as studied in e.g. Refs. 7-15. For instance, MnS inclusions within the steel microstructucture are regarded to be irreversible hydrogen traps. Considering the activation energies for the evolution of trapped hydrogen from MnS interfaces being around $72 \mathrm{~kJ} / \mathrm{mol}$, a critical temperature (in the range of $450-500^{\circ} \mathrm{C}$ ) is required to release hydrogen from the irreversible traps. ${ }^{16-18}$

Many studies have been conducted to investigate the lattice dissolution and microstructural trapping of hydrogen in iron and its alloys. The electrochemical approaches are the ones of interest in the present study.

Electrochemical permeation methods.-The electrochemical permeation techniques can provide reliable information on diffusivity and solubility of hydrogen in metals, as first introduced by Devanathan ${ }^{19}$ and further explored in various studies. ${ }^{20-22}$ In the study of Hadam

\footnotetext{
*Electrochemical Society Member.

${ }^{\mathrm{z} E-m a i l: ~ b o z d i r i k @ g m a i l . c o m ~}$
}

et al., ${ }^{2}$ electrochemical permeation experiments were performed to make a distinction between diffusible and trapped hydrogen in charged steel and iron samples.

Cyclic voltammetry based methods.-Palladium can be regarded as a model metal for studying the hydrogen absorption reaction. In literature, a CV methodology was used to study the hydrogen adsorption/absorption properties of palladium alloys. ${ }^{23}$ Some studies indicate that for thin palladium films, a sublayer rich in hydrogen, where hydrogen is trapped, contributes significantly to the global concentration of hydrogen in the film. ${ }^{24,25}$ Therefore, several studies were further conducted on thin electrodeposits of Pd alloys on Pt, Au and Rh. In the study of A.V. Uluc et al., ${ }^{26}$ hydrogen sorption/desorption properties of bulk Pd-Au and Pd-Mo-Cu alloys were investigated using the similar electrochemical methodology as in our current study. Similarly, in the further work of A.V. Uluc et al., this methodology was also successfully applied on steel to evaluate the sorption/desorption properties of hydrogen in steel with different microstructure considering the fact that the hydrogen evolution mechanism in Pd was found to be similar as the one for iron, but no complimentary technique was used to validate the findings on hydrogen related reactions. In the study of Olivares-Ramirez et al., ${ }^{27}$ the hydrogen evolution reaction is examined on different stainless steel alloys in alkaline solutions $(\mathrm{NaOH}, \mathrm{KOH})$ to determine the appropriate electrolyte, stainless steel electrode and potential for efficient hydrogen production; CV was used to clean, activate and characterize the electrode surface by considering cyclic voltammograms obtained before and after hydrogen evolution. However, absorption and desorption properties of hydrogen in steel were not investigated by electrochemical measurements in this work. In the study of Modiano et al., ${ }^{28}$ the influence of hydrogen charging on the stability of quenched and tempered boron steel membrane electrodes using a borate buffer and $\mathrm{NaOH}$ solutions was investigated by means of CV and electrochemical impedance spectroscopy. However, rather than the hydrogen sorption properties, passivation related reactions at the steel surface were the focus of this study.

Electrochemical potentiostatic oxidation method.-Hydrogen desorption from steel was studied using the hydrogen electrochemical oxidation method by Yan et al. ${ }^{29}$ The total amount of absorbed 
hydrogen (after potentiostatic charging in $\mathrm{NaOH}$ ) was determined by considering the area under the oxidation current vs time curves. From this a relationship between the hydrogen concentration and the amount of charge released during the electrochemical oxidation could be demonstrated. The effects of the solution $\mathrm{pH}$ and charging time were presented in this work. In the studies of Capelle et al. ${ }^{30}$ and Gonzalez-Sanchez et al., ${ }^{31}$ the same method was applied on pipeline steels to assess their electrochemical hydrogen absorption capacity. In this work hydrogen was introduced into steel from a $\mathrm{NS}_{4}$ solution by applying a cathodic overpotential of $200 \mathrm{mV}$ versus open-circuit potential (OCP), simulating the cathodic protection system. After Hcharging, the steel samples were taken out of solution, cleaned with water and placed in a $\mathrm{NaOH}$ solution to study the hydrogen discharging by applying a potentiostatic anodic polarization $(\mathrm{E}=+0.17 \mathrm{~V}$ vs SCE). However, it should be underlined that the various steps during all the experiments explained above were not performed immediately one after the other. Therefore, the time lag in between charging and the hydrogen oxidation procedure was not considered.

Electrolyte considerations.-In an electrochemical environment atomic hydrogen can be generated by the cathodic reduction of water, and can adsorb on a metal surface. The adsorbed hydrogen can follow two routes: either recombination to generate hydrogen gas, which can again leave the sample surface, or absorption and diffusion in the metal microstructure. The rate of hydrogen absorption can be greatly influenced by so-called "recombination poisons", which limit the hydrogen gas formation reaction. The poisons include the following elements and some of their compounds: $\mathrm{S}, \mathrm{P}, \mathrm{As}, \mathrm{Se}, \mathrm{Sn}, \mathrm{Pb}, \mathrm{Te}$. When hydrogen recombination is inhibited, the ability of atomic hydrogen to enter steel is promoted. ${ }^{32}$ Thiourea is an organo-sulfur compound with the formula $\mathrm{SC}\left[\mathrm{NH}_{2}\right]_{2}$. In the literature the mechanism is not explicitly put forward, but thiourea is considered as corrosion inhibitor and is used to promote absorption of hydrogen into host transition-metal lattices of $\mathrm{Fe}, \mathrm{Ti}, \mathrm{Pd}$ and $\mathrm{Ni}^{33}$ In the study of Hukovic, ${ }^{34}$ it was found that thiourea acts as a mixed inhibitor for ARMCO iron in acid solution (de-aerated $0.5 \mathrm{M} \mathrm{H}_{2} \mathrm{SO}_{4}$ ) up to a critical concentration. It decreases the dissolution of iron and the hydrogen evolution reaction is blocked by covering the electrode surface. Also in the study of Uluc et al., ${ }^{35}$ thiourea is used as a recombination poison to charge atomic hydrogen effectively in steel. However, to our knowledge, there is no research conducted to investigate the surface reactions of this compound on steel in alkaline solution.

To summarize, various electrochemical methods are proposed and demonstrated in literature of which $\mathrm{CV}$ and electrochemical oxidation are identified as the most promising to go toward a mechanistic investigation, which can be performed in a simple electrochemical setup. To use these methods in a reliable way, there are however some issues that need to be elucidated and scrutinized, and this is the aim of the present study. In these methods there are two steps, hydrogen charging and hydrogen discharging, which need to be considered in detail. During hydrogen charging, hydrogen should be effectively introduced into the metal avoiding hydrogen gas evolution. To overcome this challenge, a hydrogen recombination poison can be used, but its impact on the $\mathrm{H}$-interaction must be understood to allow the unambiguous identification and as such the differentiation between the roles of the various elements of the metal itself and that of the electrolyte, which is at present lacking in literature. Further, during the H-discharging step, the amount of released hydrogen should be accurately evaluated. Therefore, special attention should be paid to selecting the procedure for the discharging step in order to ensure oxidation of all the hydrogen present in the steel. Additionally in this respect, the presented approaches in literature do not take the high mobility of diffusible hydrogen in steel into account, and as such do not consider possible loss of hydrogen during the sample manipulations between charging and discharging, which is a shortcoming that will be addressed in the present study.

The aim of the present study is thus to develop a reliable electrochemical procedure based on $\mathrm{CV}$, supported by potentiostatic polarization, to study the H-sorption and desorption in and out of steel, in a quantifiable way and allowing the differentiation between the metal related effects and the electrolyte contributions. The procedure will be elaborated on plain carbon steel. This steel has a small amount of $\mathrm{MnS}$ particles (irreversible $\mathrm{H}$-trap) in its microstructure. However, they are assumed to play a negligible role in the developed electrochemical methodology in this study, since only diffusible hydrogen is desorbed at room temperature. Hence, the developed methodology is capable of monitoring diffusible hydrogen in the steel.

\section{Experimental}

Materials and methods.-Steel.-The composition of SAE 1010 used in this study is max $0.6 \mathrm{wt} \% \mathrm{Mn}, \max 0.15 \mathrm{wt} \% \mathrm{C}, \max 0.03 \mathrm{wt}$ $\% \mathrm{P}, \max 0.035 \mathrm{wt} \% \mathrm{~S}$ and $\mathrm{wt} \%$ Fe balance.

The steel is from LABOMAT Instrument \& Specialités in the form of plate $(0.5 \mathrm{~mm}$ in thickness $)$, and cut into rectangular samples $(7.2 \mathrm{~cm}$ $\times 4 \mathrm{~cm})$. The as-received samples are placed in ethanol in an ultrasonic bath to remove surface contamination and dried with pressurized air. Afterwards a mask is placed on the samples, exposing a circular area of $4.64 \mathrm{~cm}^{2}$ to the electrolyte solution during electrochemical analyses and processing.

Electrochemical methods.-Electrochemical measurements are performed with an Autolab PGSTAT302N potentiostat. The electrolyte solution is $1 \mathrm{M} \mathrm{NaOH}$, and in most experiments $8 \mathrm{~g} / \mathrm{l}$ thiourea is added as hydrogen recombination poison to avoid $\mathrm{H}_{2}$ gas evolution. The reason for selecting an alkaline solution is to prevent the steel from corroding during the electrochemical experiments. For CV and $\mathrm{H}$-charging experiments, a three electrode setup is used with the steel sample as the working electrode, a saturated $\mathrm{Ag} / \mathrm{AgCl}$ reference electrode $(+0.197 \mathrm{~V}$ vs. SHE) and a platinum grid as counter electrode. Cyclic voltammetry procedure.-The experimental procedure consists of 3 stages:

- Before charging with hydrogen the samples are submitted to two consecutive pretreatment $\mathrm{CV}$ cycles to obtain a reproducible sample surface and reference voltammogram.

- This is followed by hydrogen charging by polarizing the sample cathodically at $-1.25 \mathrm{~V}$ (vs. $\mathrm{Ag} / \mathrm{AgCl}$ ) to have water reduction on the working electrode. During the potentiostatic hydrogen charging, chronoamperometric curves are recorded to evaluate current response and to determine the amount of charge as a function of time. The charging is performed for various charging times.

- After the charging step, $5 \mathrm{CV}$ scans are recorded. The potential is cycled between $-1.25 \mathrm{~V}$ and $0.15 \mathrm{~V}$ (vs. $\mathrm{Ag} / \mathrm{AgCl}$ ), starting at $-1.25 \mathrm{~V}$, with a scan rate of $10 \mathrm{mV} / \mathrm{s}$ for most experiments. To have a better understanding of the H-desorption mechanism, the scan rate is varied in dedicated experiments $(2.5,5,10,20,30,50$ and $100 \mathrm{mV} / \mathrm{s}$ ).

Cyclic voltammetry procedure including discharging step.-Additionally, dedicated potentiostatic discharging experiments are performed. The procedure begins with the same steps as in the $\mathrm{CV}$ procedure explained above ( $2 \mathrm{CV}$ and $\mathrm{H}$-charging at $-1.25 \mathrm{~V}$ ), but is then followed by potentiostatic discharging (at $-0.90 \mathrm{~V}$ for 30 minutes) before the $5 \mathrm{CV}$ scans (starting at $-0.90 \mathrm{~V}$ ). The choice of discharging potential will be explained in the results section. This procedure is performed with the aim of verifying the hydrogen sorption/desorption and comparing the amount of charge imposed and released during charging and discharging in blank and thiourea containing $\mathrm{NaOH}$ solutions.

Linear sweep voltammetry.-To study the effect of the thiourea addition to the electrolyte on the electrochemical behavior of the steel at cathodic potentials (i.e. typically in the range where hydrogen charging is performed), Linear Sweep Voltammetry (LSV) is used. First again 2 consecutive $\mathrm{CV}$ scans are performed as presented above, and then linear sweeps are initiated from OCP down to $-1.6 \mathrm{~V}$ (vs. $\mathrm{Ag} / \mathrm{AgCl}$ ) with a scan rate of $2 \mathrm{mV} / \mathrm{s}$ in a blank $\mathrm{NaOH}$ solution versus a thiourea containing solution. 


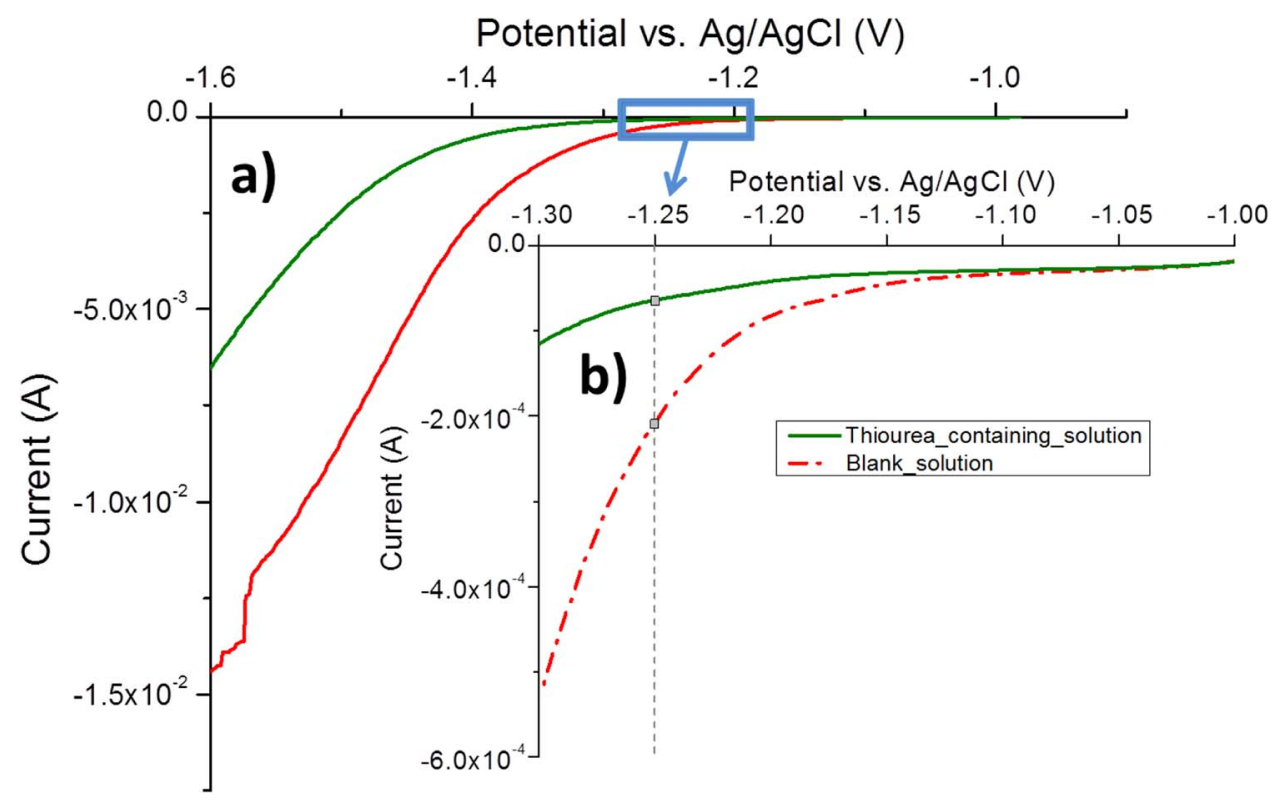

Figure 1. a) Linear Sweep Voltammogram (LSV) between $-0.98 \mathrm{~V}$ and $-1.6 \mathrm{~V}$ for the electrolyte solution w/o thiourea, b) zoom in LSV (scan rate $2 \mathrm{mV} / \mathrm{s}$ ).

In all electrochemical procedures presented, all steps are carried out at room temperature without delay between consecutive steps, unless otherwise indicated. Before starting, the electrochemical cell is de-aerated by purging with $\mathrm{N}_{2}$ gas for 15 minutes.

To quantify certain charge values from the recorded CV scans, Origin 8.5 software is used. The analysis module in the peak fitting program can determine all features of the peaks (current, potential) in $\mathrm{CV}$ as well as implement de-convolution on overlapping peaks to calculate the amount of charge released from each peak.

Hydrogen measurement procedure.-In order to determine the hydrogen saturation level, hot extraction at $300^{\circ} \mathrm{C}$ is used to measure the diffusible hydrogen content in the material, which is the same definition for diffusible hydrogen as proposed by Akiyama et al. ${ }^{36}$ To determine the hydrogen content, samples are first charged electrochemically with the same conditions as described in the general $\mathrm{CV}$-procedure. The samples are then analyzed about one minute after hydrogen charging in the hot extraction device to evaluate the hydrogen saturation time and level. The delay between charging and the hot extraction is due to the material removal from electrochemical cell and necessary surface cleaning with water and isopropanol.

The system contains an external furnace in which a pre-weighted sample is heated up to $300^{\circ} \mathrm{C}$. A mass spectrometer detects the hydrogen signal, while the software determines the hydrogen concentration of the sample based on a standard gas calibration.

\section{Results and Discussion}

Influence of thiourea.-Influence on the water reduction reaction.--In Figure 1, using LSV, steel samples are polarized with a low scan rate $(2 \mathrm{mV} / \mathrm{s})$ in the blank and the thiourea containing solutions. The curves in Figure 1 show that a higher overpotential is needed in the thiourea containing solution to draw the same current as in the blank solution. The current obtained at $-1.25 \mathrm{~V}$, at which potentiostatic hydrogen charging is performed in the $\mathrm{CV}$ procedure presented in the next sections, is nearly four times lower in a thiourea containing solution than in a blank solution (detail in inset Figure 1b). Furthermore, in the blank solution from $-1.2 \mathrm{~V}$ downwards the formation of bubbles is observed on the steel surface and from $-1.4 \mathrm{~V}$ the surface is visually completely covered. On the contrary, in a thiourea containing solution no bubble formation can be observed above -1.5 $\mathrm{V}$. From $-1.5 \mathrm{~V}$ to $-1.6 \mathrm{~V}$ some bubble formation occurs, but much less than in the blank solution.
These relative differences in current values and visual gas evolution between the blank and the thiourea containing solution confirm that the hydrogen gas evolution reaction is inhibited by thiourea, which is also suggested in the study of Ateya. ${ }^{37}$

Furthermore, this data indirectly implies that with the addition of thiourea more of the cathodically generated atomic hydrogen remains available at the surface to enter into the steel.

Influence of thiourea on the cyclic polarization behavior of steel.$\mathrm{CV}$ results obtained before and after 30 minutes of hydrogen charging are shown for a thiourea containing solution in Figure 2a. There is an increase in the first anodic response, labelled as peak $a$ (at -0.87 $\mathrm{V})$ before charging and peaks al - $a 2$ after charging (at $-0.90 \mathrm{~V}$ and $-0.87 \mathrm{~V}$, respectively). For the blank solution there is also a change in this potential region after hydrogen charging, as shown in Figure $2 b$ where a peak $a^{\prime}$ at $-0.90 \mathrm{~V}$ appears. With further cycling (not shown), peak $a^{\prime}$ decreases again in the blank solution. Note that in the thiourea solution, the current response is much higher. Therefore, in order to compare the peaks, the $\mathrm{CV}$ data in the blank solution is plotted on a tenfold lower scale.

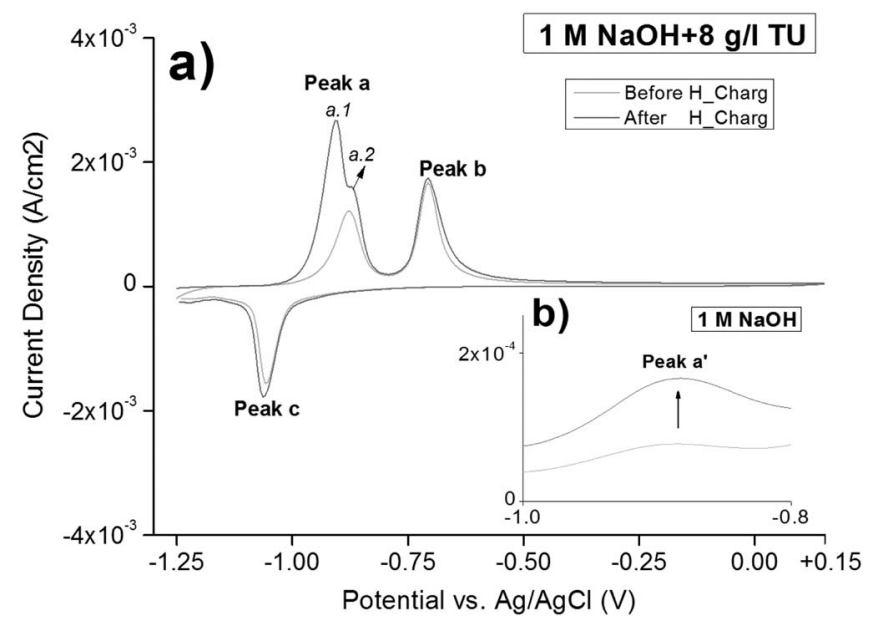

Figure 2. (a) Cyclic voltammograms obtained before and after 30 minutes of hydrogen charging in a thiourea containing solution $(8 \mathrm{~g} / \mathrm{l})$, and (b) peak $a^{\prime}$ before and after 30 minutes of hydrogen charging for the $1 \mathrm{M} \mathrm{NaOH}$ solution without thiourea (scan rate $10 \mathrm{mV} / \mathrm{s}$ ). 


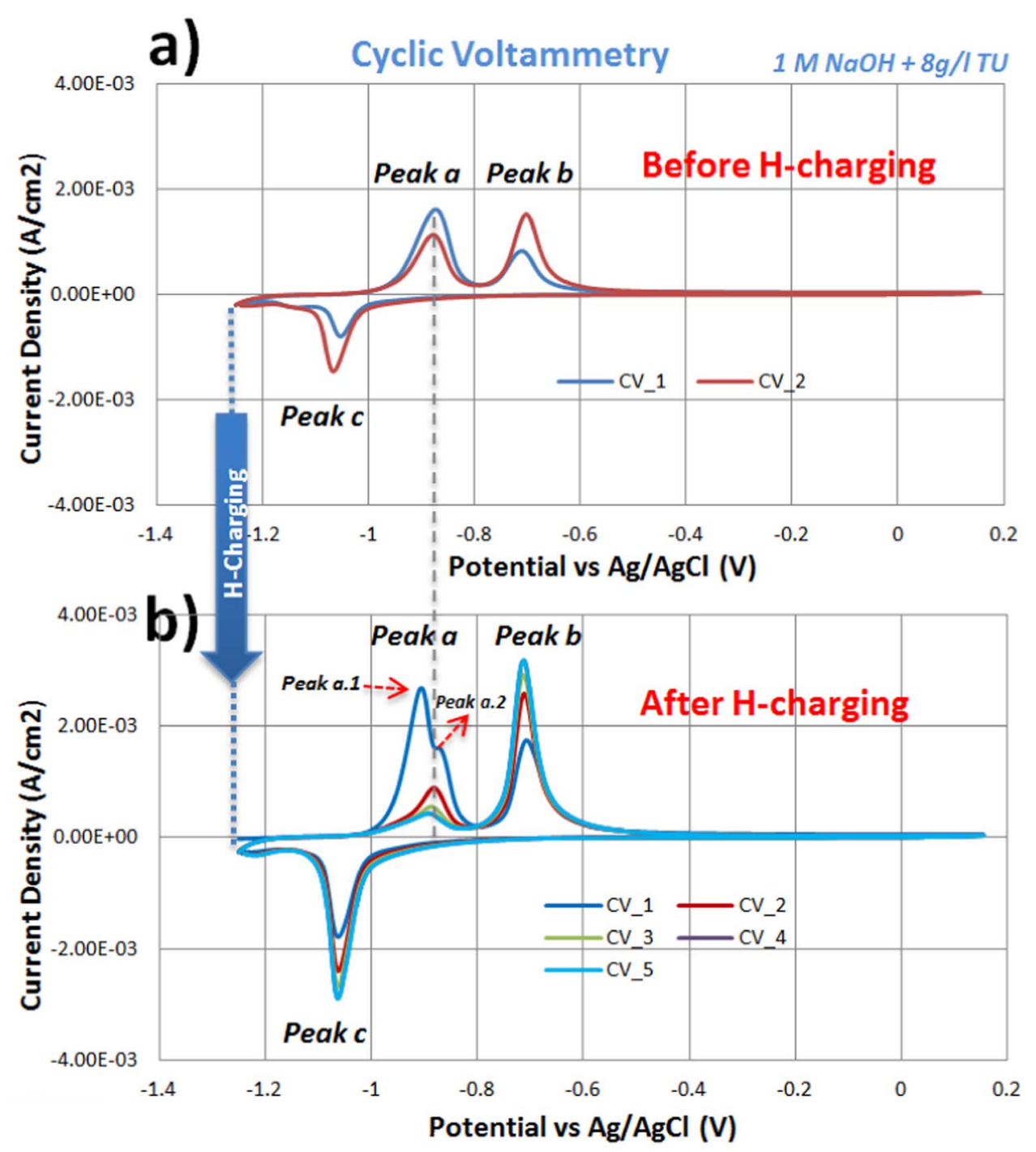

Figure 3. Overview of the procedure for cyclic voltammetry (a) two CV scans before hydrogen charging, (b) five CV scans after 30 minutes of hydrogen charging in $1 \mathrm{M} \mathrm{NaOH}$ solution containing $8 \mathrm{~g} / \mathrm{l}$ thiourea solution (scan rate $10 \mathrm{mV} / \mathrm{s}$ ).

Peak $a .1$ in the thiourea containing solution, which only appears after hydrogen charging, is at the same potential as peak $a^{\prime}$ in the blank solution. This suggests that this peak position is in both cases related to the prior hydrogen charging. Further, note that in the thiourea solution the potential of peak a.2 matches with the potential of the single peak $a$ before charging, and that in the blank solution there is no peak at this potential position. This suggests that peak a.2 is thiourea related.

Effect of hydrogen charging on the CV response.-For a better understanding of the origin of all the peaks in $\mathrm{CV}$ in relation to the hydrogen charging, the experimental $\mathrm{CV}$ procedure is illustrated in Figure 3 for the thiourea containing $\mathrm{NaOH}$ solution.

In Figure $3 \mathrm{a}$, two consecutive $\mathrm{CV}$ cycles are performed on the steel as pre-treatment before hydrogen charging. Two anodic and one cathodic response are observed in the voltammogram. Peak $a$ decreases with cycling, while peak $b$ and peak $c$ grow. The integration of peak $b$ and peak $c$ indicates that the amount of charge released from both peaks is similar. Additionally, during cycling, the color of the sample turns orange-brown in the anodic scan (from $-0.8 \mathrm{~V}$ onwards), which disappears again in the reverse scan. Peaks $b$ and $c$ are generally attributed to (hydr)oxidation/reduction reactions of steel. ${ }^{38-40}$ As these processes are not the focus of the presented work, they will not be discussed further.
In Figure $3 b$ five consecutive voltammograms recorded after potentiostatic hydrogen charging are shown. For the scanning conditions used, the first anodic response in the first $\mathrm{CV}$ scan contains two peaks labelled $a .1$ and $a .2$. In the second CV scan, peak $a .1$ is gone and only peak $a .2$ remains, showing a decreasing trend from the first to the second scan. From the third scan on, peak a.2 no longer changes significantly. Note as already mentioned in previous section, but important for further discussion, that the potential corresponding to peak a $(-0.87 \mathrm{~V})$ before hydrogen charging (as seen in the two pretreatment $\mathrm{CV}$ scans) is the same as the potential of peak a.2 after hydrogen charging.

In Figure $3 \mathrm{~b}$, peaks $b$ and $c$ increase (both to the same extent) with cycling. This can be related to the in literature reported formation of multilayers of iron oxide, ${ }^{41}$ or possibly to surface roughening. ${ }^{42}$ Note that these peaks are not noticeably influenced by the hydrogen charging duration. Hence, in the next sections, only the peaks related to the hydrogen charging procedure, peaks $a .1$ and $a .2$, will be investigated in more detail.

Influence of H-charging time.-In Figure 4 the first CV scan (out of the 5-scan procedure) after $\mathrm{H}$-charging is shown as a function of the prior hydrogen charging duration. It is observed that the shapes and heights of peak a.1 and peak $a .2$ are depending on this charging time. After 5 minutes of charging, peaks $a .1$ and $a .2$ are present with 


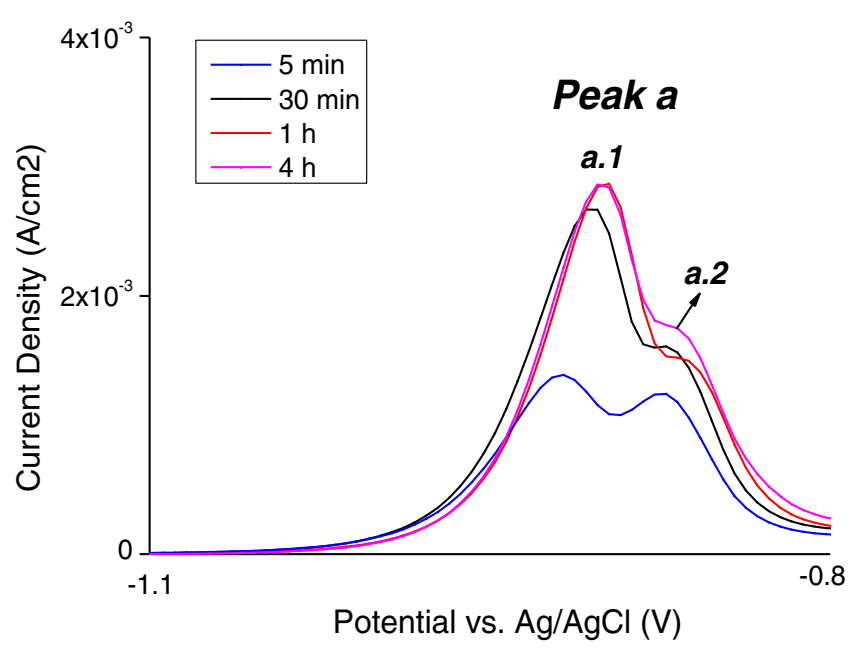

Figure 4. The first CV scans after hydrogen charging for $5 \mathrm{~min}, 30 \mathrm{~min}$, 1 hour and 4 hours in $1 \mathrm{M} \mathrm{NaOH}$ solution containing $8 \mathrm{~g} / \mathrm{l}$ thiourea (scan rate $10 \mathrm{mV} / \mathrm{s}$ ).

similar height in the first $\mathrm{CV}$ scan. With a charging of 30 minutes, both peaks have increased compared to the 5 minutes charging, with peak a.1 increasing relatively more than peak a.2. However, for longer hydrogen charging - up to 4 hours - the heights of peaks a.1 and a.2 remain at the same level as for 30 minutes of charging. This data confirms that peaks $a .1$ and $a .2$ are related to the hydrogen charging, and indicates that the steel samples used in these experiments seem saturated when charged for slightly more than 30 minutes (for the considered solution and charging conditions).

The evolution of the peaks during the 5 consecutive $\mathrm{CV}$ scans can be observed in Figures $5 \mathrm{a}$ to $5 \mathrm{~d}$ after charging for $5 \mathrm{~min}, 30 \mathrm{~min}, 1 \mathrm{~h}$ and $4 \mathrm{~h}$. From this it is clear that peaks $a .1$ and $a .2$ reduce from one scan to the next for all charging durations.

Further, in all cases peak a.l is no longer present in the second CV scan. This suggests that peak $a .1$ is related to complete $\mathrm{H}$-desorption from the steel during the first CV scan, and this seems to be independent from the prior charging duration for the used scan rate. This peak is at $-0.90 \mathrm{~V}$, which will be considered as the discharging potential in the dedicated discharging experiments in Influence of potentiostatic $\mathrm{H}$-discharging section. In all cases peak a.2 also reduces but does not disappear. As this peak is only present in the thiourea experiments, it must be coming from a thiourea related oxidation process, which is to our knowledge never assigned as such in literature.

Influence of scan rate.-The uptake and release of hydrogen in steel are time-dependent processes. To try to capture this influence experimentally as well as to get more insight in the mechanism of hydrogen desorption and thiourea triggered reactions, additional $\mathrm{CV}$ experiments were performed at different scan rates in Figure 6 (after two pre-treatment cycles and $30 \mathrm{~min}$ hydrogen charging) i.e. 2.5, 5, $10,20,30,50$ and $100 \mathrm{mV} / \mathrm{s}$. As the current densities recorded at scan rates $2.5,5$ and $10 \mathrm{mV} / \mathrm{s}$ are relatively low compared to the higher scan rates, the region of the anodic response peak $a$ of these three CVs is enlarged in Figure $6 \mathrm{~b}$ for better comparison.

The peak current densities for all occurring phenomena increase with scan rate. Peak a.1 and peak a.2, respectively associated with hydrogen desorption and a thiourea related reaction, are visually separated only at the lower scan rates. At 20 and $30 \mathrm{mV} / \mathrm{s}$, peak a.2 becomes a shoulder of peak a.1. At scan rates of 50 and $100 \mathrm{mV} / \mathrm{s}$, peak $a .1$ and peak $a .2$ fully overlap and only one single peak is observed.

For the highest scan rates of 50 (not shown) and $100 \mathrm{mV} / \mathrm{s}$ (shown in Figure 7), peak a.2 visually re-appears in the second CV scan when peak $a .1$ has decreased already significantly due to the at least partial desorption of $\mathrm{H}$ during the first scan.
By peak deconvolution, the released charges can be calculated. As for the first $\mathrm{CV}$ scan at $100 \mathrm{mV} / \mathrm{s}$ there is only one single peak, deconvolution is not performed. Although at a scan rate of $50 \mathrm{mV}$ only one single peak is seen, two peaks (peak a.1 and peak a.2) can still be discriminated by considering the second derivative of the first $\mathrm{CV}$ scan. Therefore, the charge calculation based on peak fitting is performed for all scan rates except $100 \mathrm{mV} / \mathrm{s}$, and is presented in Figure 8. Note that no error bars are visible in Figure 8 since the error for the charge values arisen from the deconvolution of the peaks (in the range of $10^{-5}$ ) was even smaller than the size of the dots.

It can be observed that with increasing scan rate, the amount of charge for peak a.1 increases slightly up to a scan rate of $30 \mathrm{mV} / \mathrm{s}$, and then remains steady. On the other hand, the amount of charge for peak a.2 decreases fast from scan rate $2.5 \mathrm{mV}$ to $5 \mathrm{mV}$, and then more smoothly with increasing scan rate. The processes responsible for the appearance of peaks $a .1$ and $a .2$ are thus time related.

Time lag between charging and $\mathrm{CV}$.-In the experiments presented above all steps in the procedure are done immediately one after the other, without interruption or intermediate sample manipulation or removal from the solution. The impact of a deliberate waiting time (with the sample remaining in solution) between the CV scans and the H-charging is shown in Figure 9, showing the first CV scan after time lags of 0 up to 10 minutes. Upon further cycling, scans 2-3-4-5 do not show an influence of this time lag anymore, so they are not shown.

It can be seen that peak a.1 decreases while peak $a .2$ increases as the time lag goes from zero to 5 minutes. After 10 minutes of waiting, peak a.1 completely disappeared and only peak $a .2$ remains. The sample is clearly changing during the time lag and the reactions which are happening during the CV scan are depending on this variable.

Influence of potentiostatic H-discharging.-In order to look more closely to the $\mathrm{H}$-desorption behavior in the $\mathrm{CV}$ procedure, a dedicated potentiostatic discharging step is included, as illustrated in Figure 10 and outlined in the Experimental section. During the polarization steps at $-1.25 \mathrm{~V}$ (for charging) and $-0.9 \mathrm{~V}$ (for discharging), current response curves are recorded and shown in Figures 10b and 10c-10d.

In Figure 10e, the first anodic response peak $a$ is now much reduced because of the deliberate prior potentiostatic discharging step, and does not change with cycling. This confirms again that peak $a .1$ in previous sections is related to hydrogen desorption.

The current during the hydrogen charging at $-1.25 \mathrm{~V}$ decreases to a stable low value, as illustrated in Figure 10b. Note that for longer charging duration (not shown) the current remains at this low value (not zero). During the polarization at $-0.9 \mathrm{~V}$ for 30 minutes, the current drops sharply in the first few seconds, as seen in Figure 10c and inset $10 \mathrm{~d}$, and reduces to nearly zero after approximately two hundred seconds. This implies that the hydrogen desorption happens very fast during this polarization step.

These discharging experiments were also performed for variable $\mathrm{H}$-charging times (between 0 and 60 minutes), in both the blank and the thiourea containing solutions (polarization data not shown). By integrating the chronoamperometric curves obtained at $-1.25 \mathrm{~V}$ and $-0.90 \mathrm{~V}$, the amount of charge and discharge values can be calculated in coulombs as a function of the H-charging time, as presented in Figure 11.

In the blank solution, the amount of charge increases steeply with charging duration. Here, the current response is related to the hydrogen gas evolution reaction. This statement is supported by the fact that the amount of charge released in the discharging experiments remains very low, indicating that there is no significant amount of hydrogen to be desorbed from the metal.

In the thiourea containing solution the current response during charging is related mainly to ab/adsorption of hydrogen in steel, and possibly some minor (which cannot be observed visually) hydrogen gas evolution. During discharging there is now a certain amount of charge released, and this even without prior hydrogen charging (so at zero charging time), which is coming from a thiourea related oxidation process and can be considered as a background current. The 

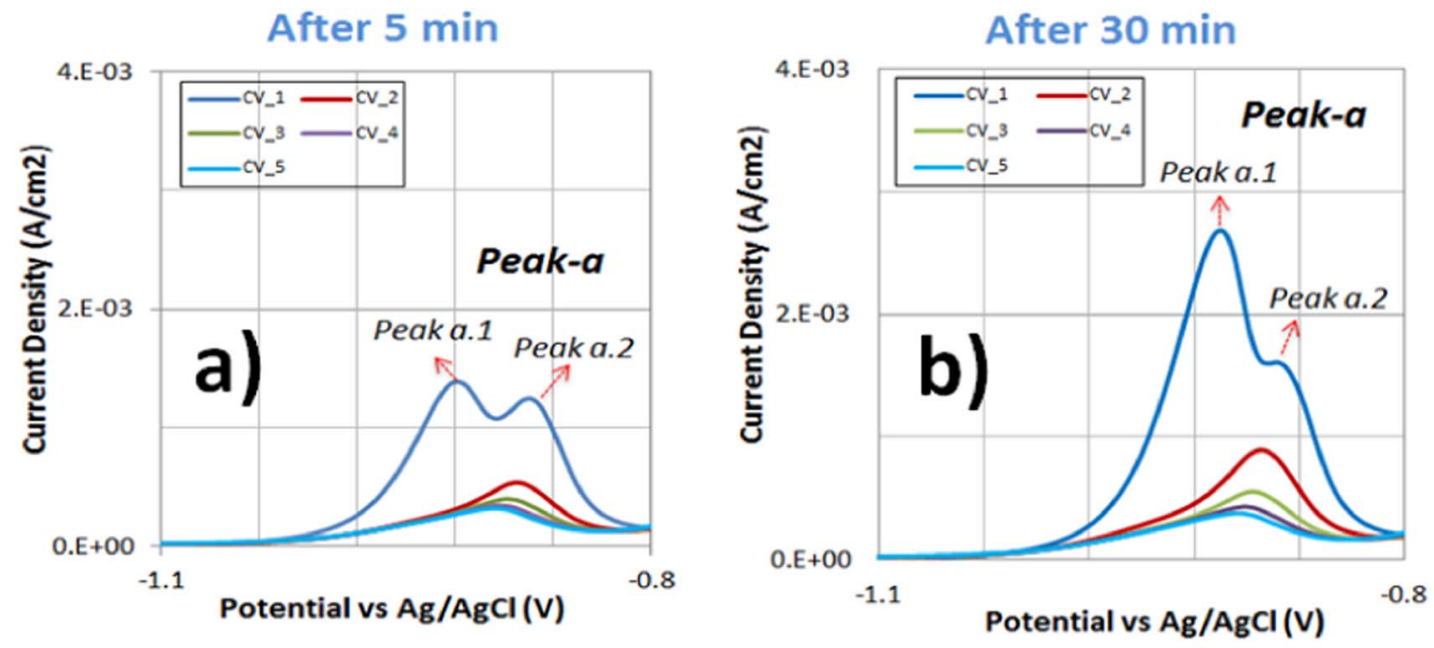

After $1 \mathrm{~h}$
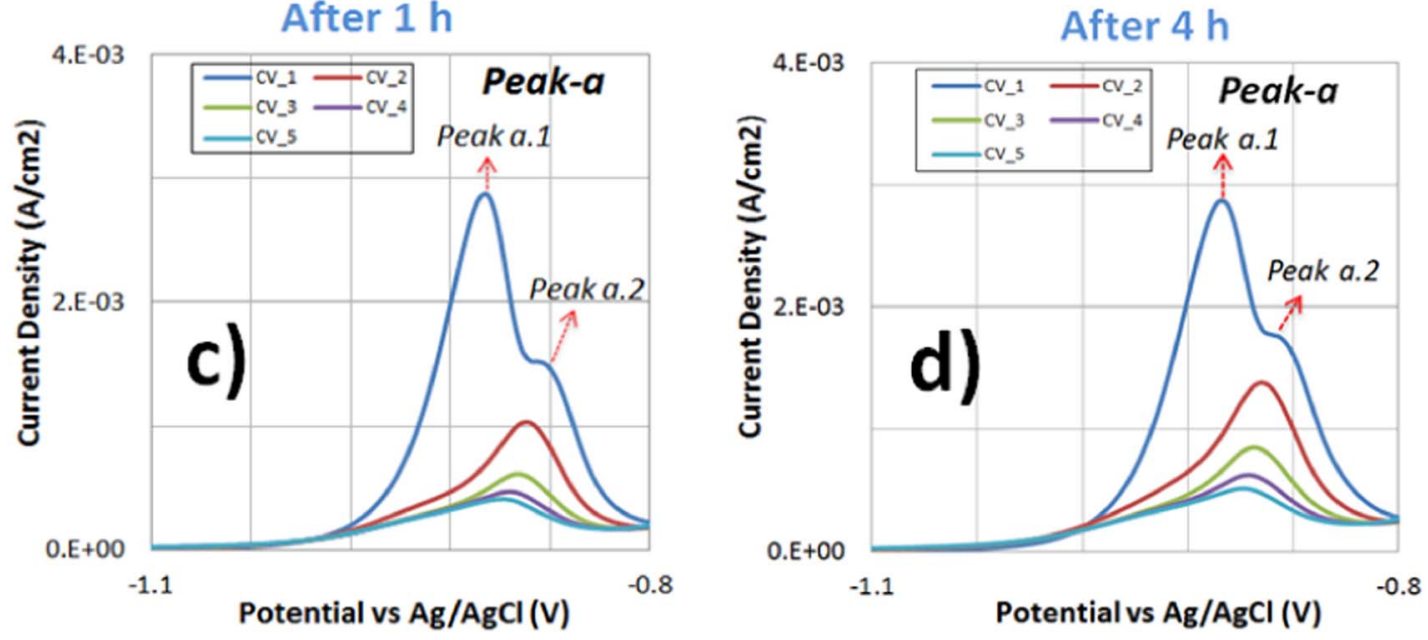

Figure 5. Overview of the 5 cyclic voltammograms obtained after charging for different times: (a) 5 minutes, (b) 30 minutes, (c) 1 hour and (d) 4 hours of hydrogen charging in $1 \mathrm{M} \mathrm{NaOH}$ solution containing $8 \mathrm{~g} / \mathrm{l}$ thiourea (scan rate $10 \mathrm{mV} / \mathrm{s}$ ).

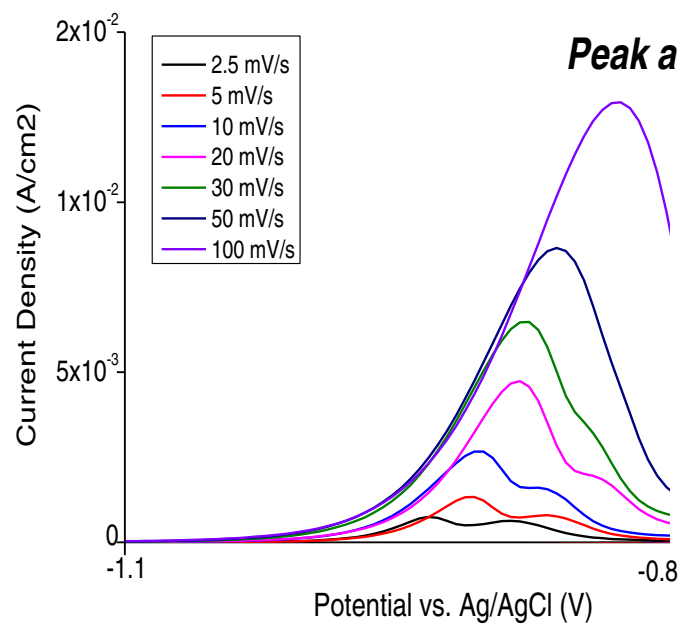

(a)

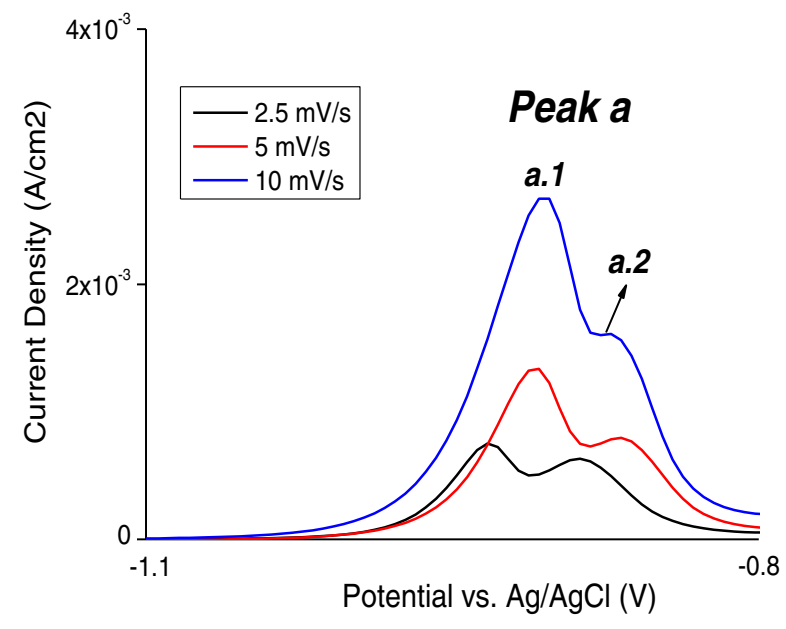

(b)

Figure 6. (a) Illustration of first CV scans obtained at different sweep rate after 30 minutes of hydrogen charging in thiourea containing solution, (b) zoom in the region of peak $a$ at a scan rate of $2.5,5$ and $10 \mathrm{mV} / \mathrm{s}$. 


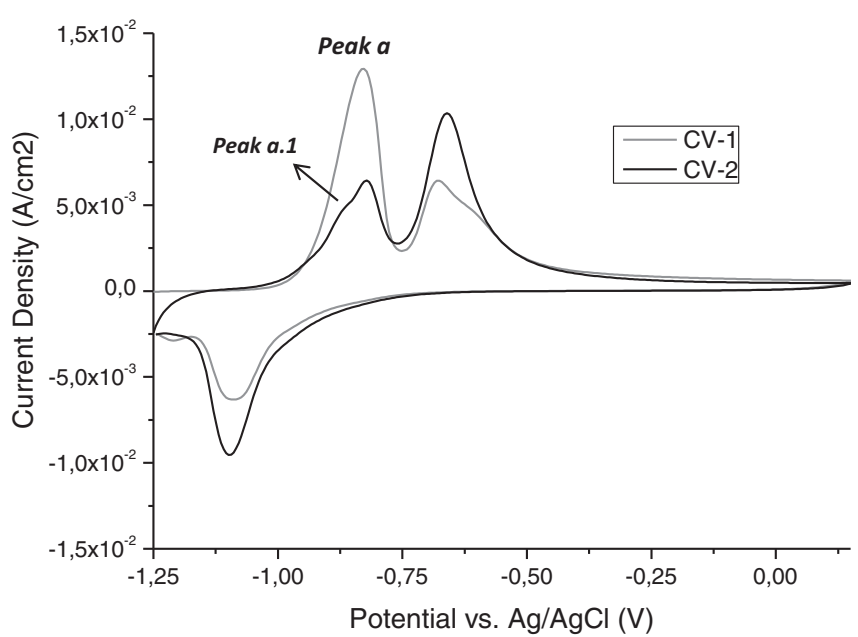

Figure 7. Illustration of initial two CV scans obtained at a scan rate of 100 $\mathrm{mV} / \mathrm{s}$ after 30 minutes of hydrogen charging in thiourea containing solution.

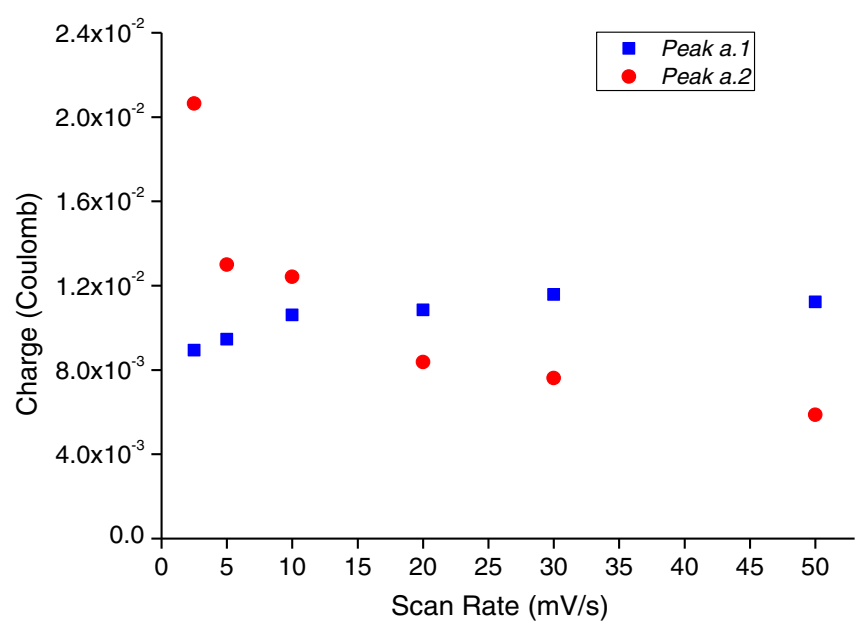

Figure 8. The influence of the scan rate on the amount of charge released from the initial CV scan after hydrogen charging.

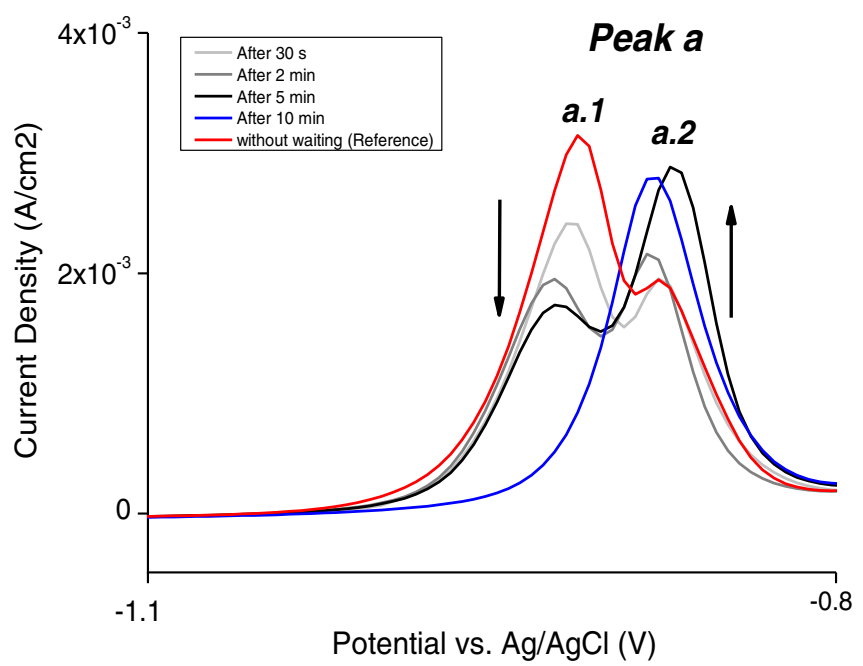

Figure 9. Influence of a deliberate time lag (30 sec., $2 \mathrm{~min}, 5 \mathrm{~min}, 10 \mathrm{~min})$ between charging and $\mathrm{CV}$ on the first anodic response in $\mathrm{CV}$ in $1 \mathrm{M} \mathrm{NaOH}$ solution containing $8 \mathrm{~g} / \mathrm{l}$ thiourea (scan rate $10 \mathrm{mV} / \mathrm{s}$ ). released charge during the discharging step increases slightly up to thirty minutes of charging $(1800 \mathrm{sec})$, and then remains constant. This corresponds with the increase of peak a.1 for up to 30 minutes of charging, but remaining at a stable value for longer charging times as was shown in Figure 4. Note that for longer H-charging than 30 minutes the current response during charging remains at a low non-zero value (as was shown in Figure 10b) - explaining the further increase of the input charge value due to the higher integrated area in the currenttime curve (based on charged calculation)- while the charge released during discharging is the same as for the 30 minutes of charging. This confirms again that after 30 minutes of charging the net amount of hydrogen going in and coming out of the steel is zero.

Evaluation of H-saturation time using Hot-extraction method.To verify our findings considering the $\mathrm{H}$-saturation time with $\mathrm{CV}$ method as well to measure diffusible hydrogen content in plain-carbon steel, hot extraction tests were performed. The increase in hydrogen content with increasing hydrogen charging times $(5 \mathrm{~min}, 30 \mathrm{~min}, 1 \mathrm{~h}$, and $4 \mathrm{~h}$ ) is illustrated in Figure 12.

According to the results of hot extraction in Figure 12, the diffusible hydrogen content increases with increasing $\mathrm{H}$-charging time and a saturation level of about $0.05 \mathrm{wppm}$ is obtained after one hour of hydrogen pre-charging.

\section{General Discussion}

In this section the detailed assignment of peak a.1 and peak a.2 is discussed as all variables can now be considered and compared.

Hydrogen desorption by oxidation: peak a.1.-Peak a.1 is only clearly present in the $\mathrm{CV}$ after $\mathrm{H}$-charging in the thiourea containing solution, where the thiourea favors the hydrogen absorption in the steel instead of the atomic hydrogen recombination to form hydrogen gas. Note that the $\mathrm{H}$-charging and the $\mathrm{CV}$ start potential are the same so that $\mathrm{H}$-oxidation is not noticeably influenced by other surface reactions. Therefore, it is suggested that oxidation of absorbed hydrogen occurs as a first reaction and appears in the first peak of CV (peak a.1), which increases with H-charging times. Peak a.l can thus be assigned to oxidation of absorbed hydrogen. The reduction tendency of the peak current with cycling is related to the fact that hydrogen is gradually desorbed during the $\mathrm{CV}$ cycling. The faster the cycling, the longer we can observe peak $a .1$ in the CV scans.

When the $\mathrm{CV}$ results are compared for different hydrogen charging times, it can be stated that peak a.1 increases up till 30 minutes of charging and then remains almost constant for longer charging times suggesting that the exposed steel is near- saturated with $\mathrm{H}$ after approximately 30 minutes of charging in the given conditions.

When the amount of charge released from peak a.l is calculated as a function of scan rate, there is a slightly increasing trend recorded from $2.5 \mathrm{mV} / \mathrm{s}$ up to $30 \mathrm{mV} / \mathrm{s}$. This can be understood when considering that hydrogen can be released from the steel in two ways: by electrochemical oxidation or by the recombination reaction if it can diffuse out of the steel before being electrochemically oxidized. This was shown for Pd-alloys by the studies of A. Czerwinski: ${ }^{43,44}$ hydrogen desorption can occur via electrochemical (charge transfer), as shown in Equation 1, and/or non-electrochemical reactions (recombination of atomic hydrogen), as shown in Equation 2:

$$
\begin{gathered}
\mathrm{H}_{\mathrm{ad}} \rightarrow \mathrm{H}^{+}+\mathrm{e}^{-} \\
\mathrm{H}_{\mathrm{ad}}+\mathrm{H}_{\mathrm{ad}} \rightarrow \mathrm{H}_{2(\mathrm{~g})}
\end{gathered}
$$

Hence, at higher scan rate the desorption of hydrogen through electrochemical reaction will be favored over its release through recombination, explaining the higher charge release at higher scan rates, until a steady state is reached. From CV it is observed that peak a.1 and peak a.2 (discussed in next section) both show a time dependent behavior, as seen from their evolution from one scan to the next, and from the $\mathrm{CV}$ experiments at different scan rates. 


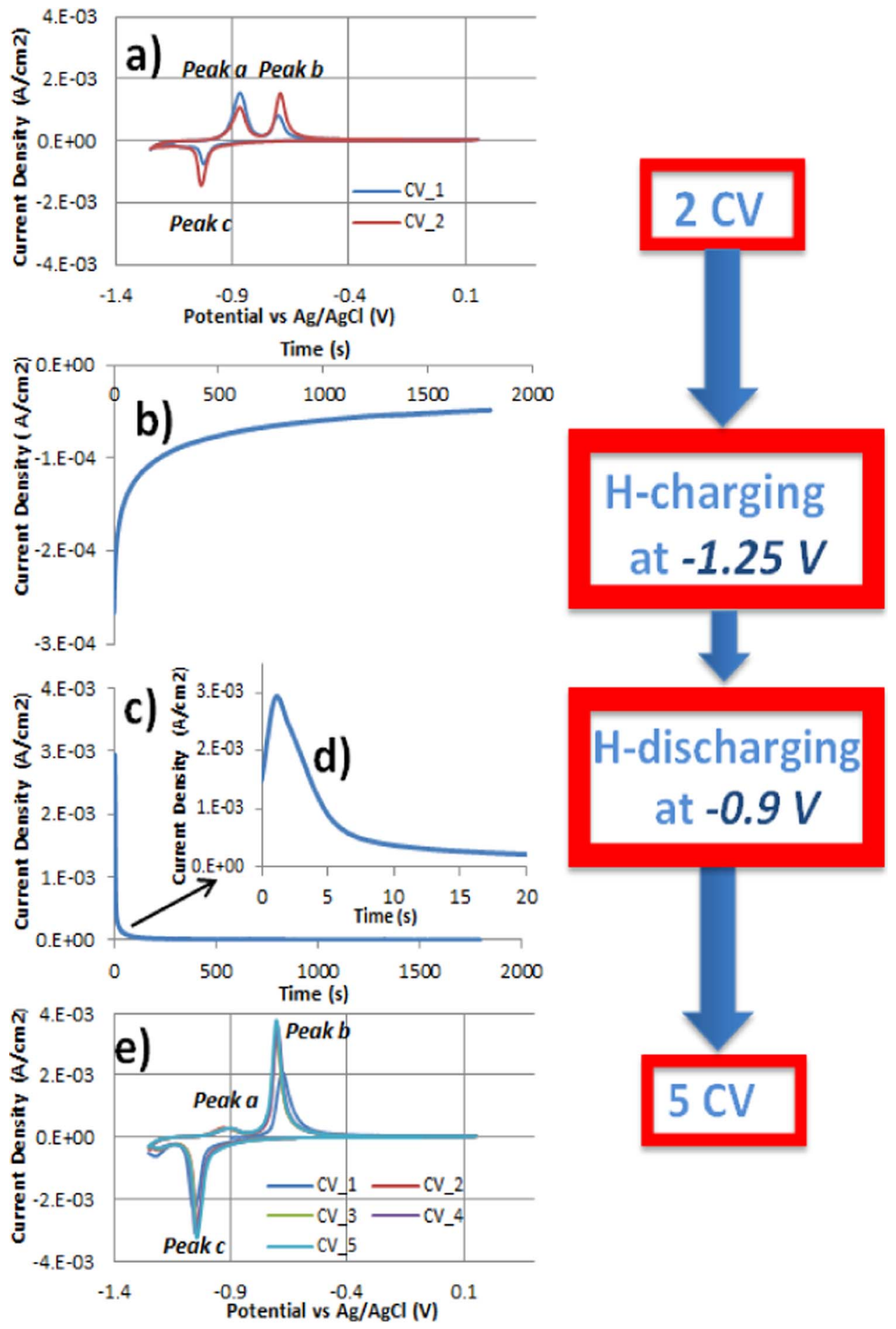

Figure 10. Overview of the CV including potentiostatic discharging procedure, (a) 2 pretreatment CV scans, (b) current density evolution during potentiostatic hydrogen charging at $-1.25 \mathrm{~V}$ for 30 minutes, (c) potentiostatic hydrogen discharging at $-0.90 \mathrm{~V}$ for 30 minutes, (d) zoom into the chronoamperometric curve at $-0.90 \mathrm{~V}$ at the beginning of the measurement, (e) $5 \mathrm{CV}$ scans (starting at $-0.90 \mathrm{~V}$ ) after 30 minutes of hydrogen charging and 30 minutes of discharging (in $1 \mathrm{M}$ $\mathrm{NaOH}$ solution containing $8 \mathrm{~g} / \mathrm{l}$ thiourea).

Time lag CV experiments also confirm that the reactions corresponding to peak a.1 and peak a.2 are time dependent. Concerning the H-desorption, with increasing time lag between charging and the subsequent CV scan, peak a.1 decreases compared to the voltammogram without time lag. Peak a.1 disappears completely after 10 minutes of waiting, which suggests that absorbed hydrogen was spontaneously desorbed during this waiting period, after which only peak a. 2 is observed in CV. Therefore, in the studied carbon steel, peak a.1 is assigned to desorption of diffusible hydrogen from the bulk of the alloy. It is known from literature that diffusible hydrogen is bound to dislocations and grain boundaries, i.e. reversible weak hydrogen traps with relatively low activation energy, thus easily releasing the hydrogen. The effusion of diffusible hydrogen is also demonstrated in the study of Perez Escobar et al., ${ }^{45}$ where diffusible hydrogen 


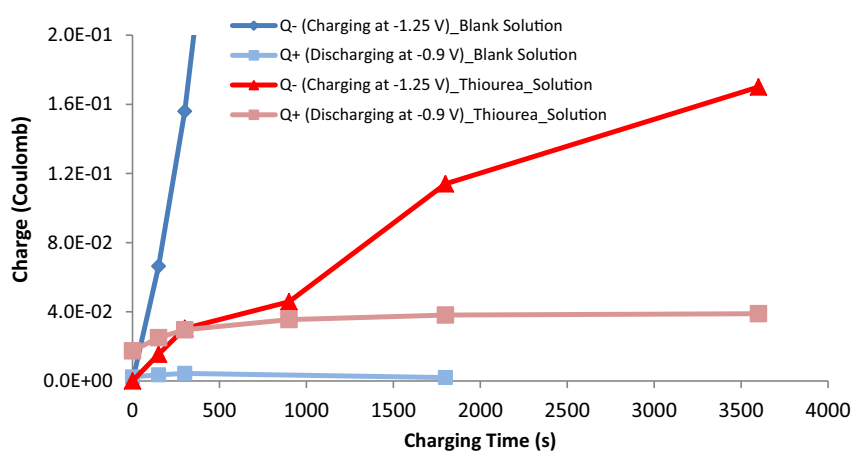

Figure 11. Overview of the charge and discharge values calculated from the chronoamperometric curves at $-1.25 \mathrm{~V}$ and $-0.9 \mathrm{~V}$ in blank and thiourea containing solutions, as a function of the variable hydrogen charging time (for a constant discharging time of 30 minutes).

immediately starts to desorb from hydrogen saturated samples after charging due to the high hydrogen diffusion coefficient in ferrite even at room temperature.

The hot extraction results, obtained for various charging times confirms that the diffusible hydrogen content rises with increasing charging time and at the same time confirms that the applied hydrogen charging procedure is successful to absorb hydrogen in the steel. Further, $\mathrm{H}$-saturation is reached between 30 minutes and one hour of hydrogen charging according to the hot extraction data. It should be noted that exact saturation time was not pinpointed in this study. However, approximately one minute is lost between hydrogen charging and hot extraction, which might induce some effusion of very mobile hydrogen out of steel. Therefore, this issue can slightly deviate the measured diffusible hydrogen amounts in the material, possibly modifying the saturation time for steel to a certain extent. The CV-method showed that the steel is saturated with hydrogen after approximately 30 minutes of hydrogen charging. However, it should also be noted that the peak a.1 in Figure 4, corresponding to $\mathrm{H}$-desorption in $\mathrm{CV}$ obtained after 1 and 4 hours of charging, seems to be slightly higher than the one for 30 minutes. Consequently, one can conclude that near $\mathrm{H}$-saturation is reached after slightly more than 30 minutes of charging steel under given conditions.

As can be seen from Figure 12, the hydrogen concentration at saturation in steel is 0.05 wppm by means of the hot-extraction method. To be able to compare this value with the one calculated from the electrochemical discharging experiment, its unit is converted to mole $/ \mathrm{cm}^{3}$ and the value corresponds to $3.9 \times 10^{-7} \mathrm{~mol} / \mathrm{cm}^{3}$. When the charge

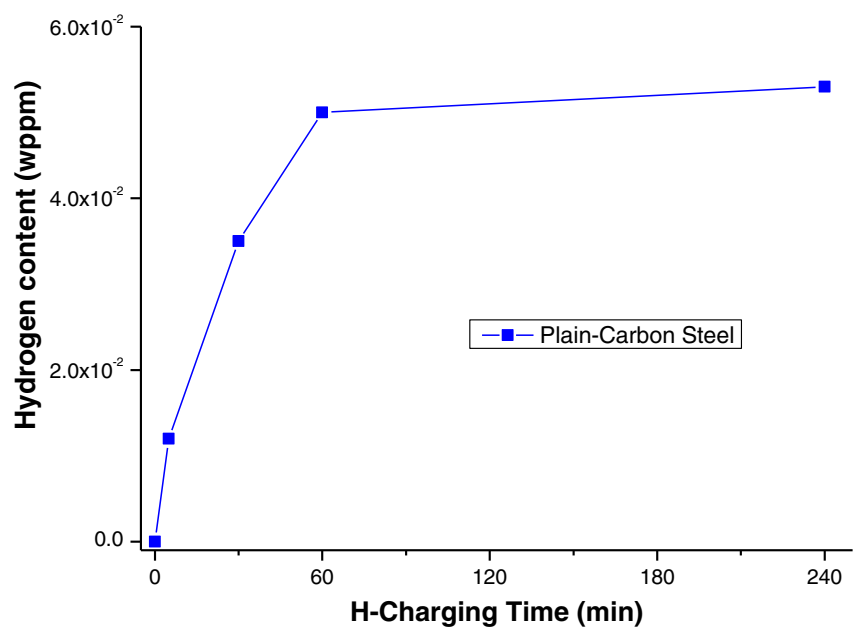

Figure 12. Hot extraction results of plain-carbon steel with variable hydrogen charging times. values are calculated from the electrochemical discharging curve (considering only the first 20 seconds of discharging), the charge value is found as $\mathrm{Q}_{\mathrm{H}(\mathrm{dis})}=1.35 \times 10^{-2} \mathrm{C} / \mathrm{cm}^{2}$. Based on Faraday's law, this corresponds to $2.8 \times 10^{-6} \mathrm{~mol} / \mathrm{cm}^{3}$. This value is nearly 10 times higher than the one obtained from the hot-extraction method. We believe that this difference can be explained by the effusion of absorbed hydrogen out of the steel during the time lag (about one minute) between $\mathrm{H}$-charging and the hot-extraction measurement, as well as by the total loss of adsorbed hydrogen from the steel due to the unavoidable sample manipulations (rinsing) prior to the hot-extraction measurement.

In order to have an estimation of the contribution of adsorbed hydrogen to the total hydrogen in the steel, the maximum charge quantity for the oxidation of adsorbed hydrogen, which can possibly be attained at a steel surface (considering a fully covering monolayer of hydrogen atoms) is calculated in addition to some data for adsorbed hydrogen from literature. Our calculation shows that the maximum charge quantity for a monolayer of adsorbed hydrogen is $2 \mathrm{mC} / \mathrm{cm}^{2}$. In the study of Pound et al., ${ }^{46}$ the charge value for adsorbed hydrogen layer was proposed to be much lower, in the range of $10^{-4} \mathrm{mC} / \mathrm{cm}^{2}$, while in study of S.A. Sheppard et al., ${ }^{47}$ the adsorption charge to real surface area was stated to be $0.21 \mathrm{mC} / \mathrm{cm}^{2}$. Considering the range of own and literature values for adsorbed hydrogen $\left(0.2-2 \mathrm{mC} / \mathrm{cm}^{2}\right)$ with respect to the total charge obtained from our $\mathrm{H}$-discharging experiment $\left(13 \mathrm{mC} / \mathrm{cm}^{2}\right)$, it can be stated that the contribution of adsorbed hydrogen to the total hydrogen being oxidized during electrochemical discharging is very low.

All this data emphasizes the importance of the continuous procedure which was used in the present $\mathrm{CV}$ setup, which allows us the measure all hydrogen, including the fast disappearing kind, which is unique compared to the in literature presented procedures.

Thiourea related oxidation reaction: peak a.2.-In the thiourea containing solution, peak $a$ in $\mathrm{CV}$ before $\mathrm{H}$-charging is observed at potential $-0.87 \mathrm{~V}$, which matches with the potential of peak $a .2$ in $\mathrm{CV}$ after H-charging. Peak a.2 is only present in the thiourea containing CV experiments and must therefore be related to thiourea. This relation is not mentioned in literature and this peak is not assigned as such. Several theories can be put forward to explain its origin.

Possibly peak $a .2$ is an oxidation reaction related to adsorbed thiourea on the surface. To our knowledge there is however no literature specifically explaining the mechanism of thiourea on steel during polarization in alkaline solution. The interaction between thiourea and palladium electrodes was studied by R. V. Bucur et al. ${ }^{48}$ It was proposed that in alkaline solution thiourea is initially adsorbed on the surface and undergoes an irreversible transformation by hydrolysis, followed by the dissociative adsorption of $\mathrm{H}_{2} \mathrm{~S}$. During the decomposition of $\mathrm{H}_{2} \mathrm{~S}$ a chemisorbed layer of sulfur is formed as well as adsorbed hydrogen. This chemisorbed sulfur can be transformed to a sulfate layer by anodic oxidation. Hence, peak $a .2$ could be coming from the oxidative transformation of a sulfur layer to sulfate. Unfortunately, using X-ray Photoelectron Spectroscopy and Raman spectroscopy (data not shown), we were not able to detect any species on the steel that could be thiourea related. We analyzed samples at various stages in the experimental procedure (before and after charging in a thiourea solution, at various potential values in the CV scan procedure etc.) but as the used XPS and Raman setups are both ex-situ, meaning that the samples must be removed from the solution, rinsed and dried before analysis, species which are only weakly adsorbed on the surface will be removed.

As a second theory to explain peak a.2, the possibility of an oxidation reaction of the steel itself, somehow triggered by thiourea, must be considered. B.G. Pound et al. ${ }^{49}$ indicated that iron can undergo a reaction with $\mathrm{H}_{2} \mathrm{~S}$, forming a $\mathrm{FeS}$ compound (mackinawite), which is non-adherent and readily spalls from the metal surface. There is also a possibility for the further oxidation of $\mathrm{FeS}$ (mackinawite) to form $\mathrm{FeO}-\mathrm{OH}$, as demonstrated in the study of J. Ning. ${ }^{50}$ But, like mentioned before, we were not able to confirm any such theory; $\mathrm{FeO}$ and 
FeO-OH compounds were detected with XPS and Raman, but at no stage we were able to detect a S-containing (intermediate) compound.

What has become clear however is that the process(es) at the origin of peak a.2 is (are) time dependent. With increasing scan rate, peak $a .2$ becomes less prominent in $\mathrm{CV}$ and the amount of charge released from peak a.2 decreases. On the other hand, with increasing time lag between charging and the CV scans, peak a.2 increased (while peak a.1 decreased as discussed above). This points toward the time dependent formation of an absorbed layer on the surface, which is oxidized at peak a.2. However, additional polarization experiments (data not shown) also indicated that the deliberate avoidance of peak $a .2$ (by starting the $\mathrm{CV}$ scan above the peak $a .2$ potential) has an influence on the heights of the steel oxidation/reduction peaks $b$ and $c$, supporting the theory that peak $a .2$ is an additional steel oxidation reaction triggered by thiourea.

Dedicated in-situ analyses are planned to shed more light on the responsible processes for the thiourea related oxidation peak. In particular, in-situ Raman will be used.

\section{Conclusions}

In the present work we succeeded in gaining a better understanding of the CV behavior of hydrogen charged steel in an alkaline solution containing thiourea. The study confirms that thiourea is an efficient hydrogen recombination poison, but at the same time demonstrates that thiourea is playing an active role in the $\mathrm{CV}$ behavior. An advancement compared to the current literature it that we were able to identify the peak related to the $\mathrm{H}$-desorption and discriminate it from a second anodic peak coming from a thiourea triggered oxidation process. Unfortunately we were not able to assign this second peak with certainty yet.

Further, the methodology consisting of three stages, i.e. CV pretreatment, potentiostatic charging, CV discharging, that was developed is able to give reproducible data on H-sorption/desorption properties of steel. Critical in the developed procedure, distinguishing it from those reported in literature, is that all the steps are performed consecutively without delay between steps, so that all hydrogen going in and coming out of the steel, including the diffusible hydrogen, can be monitored. Various charging times provide an insight in the $\mathrm{H}$-saturation level of the steel, and various scan rates were tested in the CV procedure to have experimental access to time related influences. The better understanding of the various oxidation peaks in the $\mathrm{CV}$ response and the continuous procedure, which was elaborated, result in a reliable methodology to characterize the hydrogen sorption and desorption in steel. The hot extraction technique also confirms that the diffusible hydrogen content rises with increasing charging time implying that the hydrogen charging procedure is able to absorb hydrogen in steel as well as its further detection by CV method. Comparison of the amount of hydrogen detected by the hot-extraction method with the one of the electrochemical procedure points out the importance of having no interruption between the various steps of the hydrogen measurement procedure to avoid spontaneous hydrogen loss from steel. This procedure is now ready for testing on other steel alloys with more complex microstructures.

\section{Acknowledgments}

The authors gratefully acknowledge AVN (Association Vinçotte Nuclear) and BOF-UGent (grant nr: BOF15/BAS/06) for the financial support of this $\mathrm{PhD}$ project. We would also like to thank postdoc researcher Reynier Inocente Revilla Castillo of the SURF research group at VUB (Vrije Universiteit Brussel) as well as several $\mathrm{PhD}$ students at VUB and Ghent University; Lorenzo Vecchi, Emilie Van den Eeckhout, Aurélie Laureys for the valuable discussions. Lastly, thanks go to Bart Lippens for the many steel sample preparations for the electrochemical experiments.

\section{ORCID}

Berk Ozdirik (D) https://orcid.org/0000-0001-6525-6160

\section{References}

1. Gaseous Hydrogen Embrittlement of Materials in Energy Technologies, Vol. 2, Ch, 4, "Hydrogen diffusion and trapping in metals," Edited by R. P. Gangloff and B. P. Somerday, (2012).

2. U. Hadam and T. Zakroczymski, "Absorption of hydrogen in tensile strained iron and high-carbon steel studied by electrochemical permeation and desorption techniques", International Journal of Hydrogen Energy, 34, 2449 (2009).

3. A. McNabb and P. K. Foster, "A new analysis of the diffusion of hydrogen in iron and ferritic steels,", Trans Metall Soc AIME, (1963).

4. R. A. Oriani, "The diffusion and trapping of hydrogen in steel", Acta Metall, 18, 147 (1970).

5. J. P. Hirth, "Effects of hydrogen on the properties of iron and steel,", Institute of Metals Lecture The Metallurgical Society Of AIME, Metal Trans A, (1980).

6. M. Iino, "Analysis of irreversible hydrogen trapping", Acta Metal, 30(2), 377 (1982).

7. Richard L. S. Thomas, John R. Scully, and Richard P. Gangloff, "Internal hydrogen embrittlement of ultrahigh-strength AERMET 100 steel", Metallurgical and Materials Transactions A, 34A(2), 327 (2003).

8. D. Pérez Escobar, E. Wallaert, L. Duprez, A. Atrens, and K. Verbeken, "Thermal desorption spectroscopy study of the interaction of hydrogen with TiC precipitates", Metals and Materials International, 19(4), 741 (2013).

9. E. Wallaert, T. Depover, M. Arafin, and K. Verbeken, "TDS evaluation of the hydrogen trapping capacity of $\mathrm{NbC}$ and $\mathrm{NbN}$ precipitates", Metallurgical and Materials Transactions A-Physical Metallurgy and Materials Science, 45A(5), 2412 (2012).

10. T. Depover and K. Verbeken, "The effect of TiC on the hydrogen induced ductility loss and trapping behavior of Fe-C-Ti alloys ", Corrosion Science, 112, 308 (2016).

11. T. Depover and K. Verbeken, "Evaluation of the effect of V4C3 precipitates on the hydrogen induced mechanical degradation in Fe-C-V alloys", Materials Science and Engineering A, 675, 299 (2016).

12. T. Depover, E. Wallaert, and K. Verbeken, "Hydrogen trapping and hydrogen induced mechanical degradation in lab cast Fe-C-Cr alloys", Materials Science and Engineering A, 669, 134 (2016).

13. T. Depover and K. Verbeken, "Evaluation of the role of $\mathrm{Mo}_{2} \mathrm{C}$ in hydrogen induced ductility loss in Q\&T Fe-C-Mo alloys", International Journal for Hydrogen Energy, 41, 14310 (2016).

14. T. Depover, O. Monbaliu, E. Wallaert, and K. Verbeken, "Effect of Ti, Mo and Cr Based Precipitates on the Hydrogen Trapping and Embrittlement of Fe-C-X Q\&T Alloys", International Journal of Hydrogen Energy, 40, 16977 (2015).

15. M. Koyama, A. Bashir, M. Rohwerder, S. V. Merzlikin, E. Akiyoma, K. Tsuzaki, and D. Raabe, "Spatially and kinetically resolved mapping of hydrogen in a twinninginduced plasticity steel by use of scanning kelvin probe force microscopy", Journal of the Electrochemical Society, 12, 638 (2015).

16. M. A. M. Bonab, "Evaluation of hydrogen induced cracking behavior of API X70 pipeline steel at different heat treatments", International Journal of Hydrogen Energy, 39, 6076 (2014).

17. J. L. Lee and J. Y. Lee, "Hydrogen trapping in AISI 4340 steel", Metal Science, 17, 426 (1983).

18. J. Y. Lee and S. M. Lee, "Hydrogen trapping phenomena in metals with B.C.C and F.C.C crystal structures by the desorption thermal analysis technique", Surface and Coating Technology, 28, 301 (1986).

19. M. A. V. Devanathan, "The Adsorption and Diffusion of Electrolytic Hydrogen in Palladium", Proc. Royal Soc. London Ser. A - Math. Phys. Sci., 270(1340), 90 (1962).

20. B. G. Pound, "Hydrogen trapping in high-strength steels", Acta Metal, 46(16), 5733 (1998).

21. M. Y. Chi, Y. F. Wu, J. K. Wu, and D.-Y. Lin, "Hydrogen embrittlement susceptibility and permeability of two high strength steels", Corrosion Science, 48, 1926 (2006).

22. E. Fallahmohammadi, F. Bolzoni, and L. Lazari, "Measurement of lattice and apparent diffusion coefficient of hydrogen in X65 and F22 pipeline steels", International Journal of Hydrogen Energy, 38, 2531 (2013).

23. C. Gabrielli, P. P. Grand, A. Lasia, and H. Perrot, "Investigation of hydrogen adsorption and absorption in palladium thin films", Journal of Electroanalytical Chemistry, 322, 373 (1992).

24. Y. Li and Y. T. Cheng, "Hydrogen diffusion and solubility in palladium thin films", International Journal of Hydrogen Energy, 21, 281 (1996)

25. J. Horkans, "The hydrogen region of the cyclic voltammetry of Pd: The effect of $\mathrm{pH}$ and anion", Journal of Electroanalytical Chemistry, 209, 371 (1986).

26. A. V. Uluc, J. M. C. Mol, H. Terryn, and A. J. Bottger, "Hydrogen sorption and desorption related properties of Pd-alloys determined by cyclic voltammetry", Journal of Electroanalytical Chemistry, 734, 53 (2014).

27. J. M. Olivares-Ramirez, M. L. Campos-Cornelio, and J. Uribe, Godinez, E. Borja-Arco and R. H. Castellanos, "Studies on hydrogen evolution reaction on different stainless steel", International Journal of Hydrogen Energy, 32, 3170 (2005).

28. S. Modiano, J. A. Carreno, C. S. Fugivara, A. V. Benedetti, and O. R. Mattos, "Effect of hydrogen charging on the stability of SAE 10 B22 steel surface in alkaline solutions", Journal of Electrohimica Acta, 51, 641 (2005).

29. M. Yan and Y. Weng, "Study on hydrogen absorption of pipeline steel under cathodic charging", Corrosion Science, 48, 432 (2006).

30. J. Capelle, I. Dmytrakh, and G. Pluvinage, "Comparative assessment of electrochemical hydrogen absorption by pipeline steels with different strength", Corrosion Science, 52, 1554 (2010).

31. J. A. Gonzales-Sanchez, A. L. Ruvalcaba, O. Billy, and L. R. Dzib-Perez, "Determination of sub-surface hydrogen content in the API-X52 and API X65 pipeline carbon steels", 13th International Conference, Problems of Corrosion and Corrosion Protection of Structural Materials, pp. 301-306, (2016).

32. J. Ćwiek, "Hydrogen degradation of high-strength steels", Journal of achievements in materials and manufacturing engineering, 37, 193 (2009). 
33. G. Jerkiewicz, J. J. Borozdzinski, and W. Chrzanowski, "Examination of factor influencing promotion of H-absorption into metals by site-blocking elements", The Electrochemical Society Proceedings, 94-21, 44 (1995).

34. M. Metikoš-Hukovič, R. Babić, Z. Grubač, and S. Brinić, "Impedance investigation of corrosion inhibition of Armco iron by thiourea", Journal of Applied Electrochemistry, 26(4), 443 (1996).

35. A. V. Uluc, F. D. Tichelaar, H. Terryn, and A. J. Böttger, "The role of heat-treatment and alloying elements on hydrogen uptake in Aermet 100 ultrahigh-strength steel", Journal of Electroanalytical Chemistry, 739, 130 (2015).

36. E. Akiyama, K. Matsukado, M. Wang, and K. Tsuzaki, "Evaluation of hydrogen entry into high strength steel under atmospheric corrosion", Corrosion Science, 52, 2758 (2010).

37. B. G. Ateya, B. E. El-Anadouli, and F. M. El-Nizamy, "The adsorption of thiourea on mild steel", Corrosion Science, 24(6), 509 (1984).

38. D. D. MacDonald and B. Roberts, "The cyclic voltammetry of carbon steel in concentrated sodium hydroxide solution", Electrochimica Acta, 23, 781 (1977).

39. R. S. S. Guzman, J. R. Vilche, and A. J. Arvia, "The potentiodynamic behaviour of iron in alkaline solution", Electrochim. Acta, 24, 395 (1979).

40. A. Hugot-Le Goff, J. Flis, N. Boucherit, S. Joiret, and J. Wilinski, "Use of raman spectroscopy and rotating split ring disc electrode for identification of surface layers on iron in $1 \mathrm{M} \mathrm{NaOH",} \mathrm{Journal} \mathrm{of} \mathrm{Electrochemical} \mathrm{Society,} \mathrm{137(9),} 2684$ (1990).

41. D. Geana, A. A. Elmiligy, and W. J. Lorenz, "Electrochemical behavior of iron in alkaline sulfate solutions", Journal of Applied Electrochemistry, 4(4), 337 (1974).
42. O. Khaselev and J. M. Sykes, "In-situ electrochemical tunneling microscopy studies on the oxidation of iron in alkaline solution", Electrochimica Acta, 42(15), 2333 (1997).

43. A. Czerwinski, M. Grden, and M. Łukaszewski, "Dual mechanism of hydrogen desorption from palladium alloys postulated on the basis of cyclic voltammetric studies", Journal of Solid State Eletrochemistry, 8, 411 (2004)

44. M. Łukaszewski, K. Kusmierczyk, J. Kotowski, H. Siwek, and A. Czerwinski, "Electrosorption of hydrogen into palladium-gold alloys", Journal of Solid State Electrochemistry, 7, 69 (2003).

45. D. Perez, Escobar, L. Duprez, A. Atrens, and K. Verbeken, "Influence of experimenta parameters on thermal desorption spectroscopy measurements during evaluation of hydrogen trapping", Journal of Nuclear Materials, 450, 32 (2014).

46. B. G. Pound, "The Application of a Diffusion/Trapping Model for Hydrogen lngress in High-Strength Alloys", Corrosion Science, 45, 18 (1998).

47. S. A. Sheppard, S. A. Campbell, J. R. Smith, G. W. Lloyd, T. R. Ralph, F. C. Walsh, and Analyst, "Electrochemical and microscopic characterisation of platinum-coated perfluorosulfonic acid (Nafion 117) materials", The Analyst, 123, 1923 (1998).

48. R. V. Bucur and P. Marginean, "Interaction between thiourea and palladium electrodes", Electrochimica Acta, 29(100), 1297-1303 (1984).

49. "Geothermal corrosion of iron and steel,", B. G. Pound, G. A. Wright, and R. M. Sharp, Auckland, N. Z, New Zealand Energy Research and Development Committee, (1986).

50. J. Ning, Y. Zhneg, D. Young, B. Brown, and S. Nesic, "A thermodynamic study of hydrogen sulfide corrosion of mild steel", NACE International Corrosion Publication, (2013). 